\section{AB0754 COMPARISON OF COMPOSITE INDICES TAILORED FOR PSORIATIC ARTHRITIS TREATED WITH CSDMARDS AND BDMARDS: A LONGITUDINAL OBSERVATIONAL STUDY}

F.M. Perrotta, A. De Socio, E. Lubrano. Medicina e scienze della salute, Università degli studi del Molise, Campobasso, Italy

Background: Remission or low disease activity should be the target of therapy in chronic inflammatory arthritis as well as in Psoariatic arthritis (PsA). In a complex disease such as PsA, several methods are available to define remission that comprise the assessment of different clinical features.

Objectives: The aim of this study was to compare the composite indices tailored for PsA in both patients treated with csDMARDs and bDMARDs.

Methods: Adult PsA patients classified with CASPAR criteria and with $>6$ months follow up treated with first csDMARDs and bDMARDs were consecutively enrolled in our outpatient clinic. To assess disease activity, composite indices tailored for PsA namely DAPSA, CDAPSA, PASDAS, MDA (5/7) and MDA (7/7) were used. DAPSA and CDAPSA score $\leq 4$, MDA $7 / 7$ and PASDAS $\leq 1.9$ identified remission while MDA 5/7and PASDAS $<3.2$ the minimal disease activity and inactive disease criterion ${ }^{1-5}$

Results: One hundred nine PsA patients were enrolled. Of this, 79 patients were in stable treatment with bDMARDs and 30 with csDMARDs. Overall, 28 (25.6\%), $23(21.1 \%), 19(17.4 \%), 54(49.5 \%), 13(11.9 \%)$ and $35(32.1 \%)$ PsA patients were in cDAPSA remission, DAPSA remission, MDA 7/7, MDA 5/7, PASDAS $\leq 1.9$ and PASDAS $<3.2$. Patients in bDMARDs had a significantly low median DAPSA, CDAPSA and PASDAS score than patients treated with csDMARDs (table 1). Overall, the concordance between the indices ranging from slight to good.

Table 1. Demographic and clinical disease activity characteristics in patients treated with bDMARDs and csDMARDs

\begin{tabular}{lccc}
\hline & bDMARDs $(\mathrm{n}=79)$ & csDMARDs $(\mathrm{n}=30)$ & $\mathrm{P}$ value \\
\hline Female/male & $38 / 41$ & $16 / 14$ & $\mathrm{~ns}$ \\
Mean age (SD), years & $52.7(12.4)$ & $51.6(12.3)$ & $\mathrm{ns}$ \\
Disease duration (SD), years & $7.8(9.3)$ & $6.6(8.2)$ & $\mathrm{ns}$ \\
PASI, median (25th-75th percentile) & $0.3(0-0.6)$ & $1.5(0-3.2)$ & 0.02 \\
Enthesitis (LEI) median (25th-75th percentile) & $0(0-1)$ & $1(0-3)$ & $<0.01$ \\
CRP, mg/dl (25th-75th percentile) & $0.3(0.16-0.49)$ & $0.3(0.2-0.76)$ & $\mathrm{ns}$ \\
PASDAS, median (25th-75th percentile) & $3.28(2.69-3.72)$ & $4.43(3.73-4.76)$ & $<0.01$ \\
MDA 5/7, n (\%) & $49(62)$ & $5(16.6)$ & $<0.01$ \\
MDA 7/7, n (\%) & $16(20.2)$ & $3(10)$ & $\mathrm{ns}$ \\
DAPSA, median (25th-75th percentile) & $6.8(3.7-9.57)$ & $18.1(16.5-31.5)$ & $<0.01$ \\
cDAPSA, median (25th-75th percentile) & $6.5(3.5-9.5)$ & $17.5(11.2-26.9)$ & $<0.01$ \\
\hline
\end{tabular}

PASI: psoriasis area severity index; LEI: Leeds enthesitis index; CRP: C-reactive protein; PASDAS: psoriatic arthritis disease activity score; MDA: minimal disease activity, DAPSA: disease activity index for psoriatic arthritis.

Conclusions: PsA patients in bDMARD are more likely to reach a status of MDA and remission in respect to csDMARDs. PASDAS $\leq 1.9$ and MDA 7/7 seem to be stringent remission criteria.

References:

[1] Coates LC et al. Defining disease activity in psoriatic arthritis: a proposed objective target for treatment. Ann Rheum Dis 2010;69:48-53.

[2] Coates LC et al. Defining low disease activity states in psoriatic arthritis using novel composite disease instruments. J Rheumatol 2016;43:371-5.

[3] Helliwell PS et al. The development of candidate composite disease activity and responder indices for psoriatic arthritis (GRACE project). Ann Rheum Dis 2013;72:986-91.

[4] Schoels $\mathrm{MM}$ et al. Disease activity in psoriatic arthritis (PsA): defining remission and treatment success using the DAPSA score. Ann Rheum Dis 2016;75:811-8

[5] Nell-Duxneuner VP et al. Evaluation of the appropriateness of composite disease activity measures for assessment of psoriatic arthritis. Ann Rheum Dis 2010;69:546-49.

Disclosure of Interest: None declared

DOI: 10.1136/annrheumdis-2017-eular.4359

\section{AB0755 DEPRESSION AND ANXIETY MAY CONTRIBUTE TO HIGHER DISEASE ACTIVITY AND WORSE QUALITY OF LIFE IN PSORIATIC ARTHRITIS}

$\underline{\text { F. Farkas }}^{1}$, N. Ikumi ${ }^{1}$, A. Szentpetery ${ }^{1}$, B. Kirby ${ }^{2}$, O. FitzGerald ${ }^{1} .{ }^{1}$ Department of Rheumatology; ${ }^{2}$ Department of Dermatology, St. Vincent's University Hospital, Dublin, Ireland, Dublin, Ireland

Background: Psoriatic arthritis (PsA) is a heterogeneous disease with variable types of joint involvement, extra-articular features, including skin psoriasis, and with well-known comorbidities such as depression and anxiety ${ }^{1}$. Composite Psoriatic Disease Activity Index (CPDAI) adequately assesses disease activity in this complex condition ${ }^{2}$. To date, no study has evaluated the relationship between depression/anxiety scores and CPDAI in PsA.

Objectives: The aim of this study was to compare 1) depression/anxiety scores;2) physician-assessed and patient-reported outcome measures (PROMs) between patients with $\mathrm{CPDAl}<4$ suggesting low disease activity versus with $\mathrm{CPDAl}>4$ reflecting moderate or severe disease activity in PsA.

Methods: PsA patients fulfilling the CASPAR criteria were recruited. Patients un- derwent musculoskeletal and skin assessments (TCJ68, SJC66, Leeds enthesitis index, dactylitis digit score and PASI) and they have completed questionnaires on physical function and health-related quality of life (HAQ, PsAQoL, DLQI, EQ-5D, BASDAI, BASFI, ASQoL, BRAF-NRS, pain and general health VAS). Patients were assessed for depression/anxiety using the Hospital Anxiety and Depression Scale (HADS-A and HADS-D) and Penn State Worry Questionnaire (PSWQ). Data were analyzed using Mann Whitney, Chi-square tests and linear regression model.

Results: 100 PsA patients were recruited; 57 presented with CPDAI $\leq 4$ (age $52.7 \pm 9.46$ years) and 43 with $\mathrm{CPDAl}>4$ (age $52 \pm 11.82$ years). Patients with CPDAl $>4$ had significantly higher TCJ68 $(p<0.001)$, Leeds enthesitis index $(p=0.015)$ and significantly worse HAQ, BASDAI and ASQoL scores. There was no significant difference in other items of CPDAI between the two groups. Patients with $\mathrm{CPDAl}>4$ had significantly higher HADS-D, HADS-A and PSWQ scores $(p<0.001 ; p<0.001 ; p=0.001$, respectively) and significantly worse $P R O M s$, including PSAQoL, EQ-5D score, BASFI, BRAF-NRS, pain and general health VAS (Table 1). Multiple regression analysis revealed significant relationship between PsAQoL, BASFI and CPDAI ( $B=0.311, p=0.0093$; $B=0.568, p<0.0001$, respectively).

Table 1. Comparison of patient-reported outcome measures between CPDAI $\leq 4$ and CPDAI $>4$ groups

\begin{tabular}{lccc}
\hline PROMs & $\begin{array}{c}\text { CPDAI }<4 \\
\mathrm{n}=57\end{array}$ & $\begin{array}{c}\text { CPDAI }>4 \\
\mathrm{n}=43\end{array}$ & p value \\
\hline HADS-D & $2.32 \pm 2.53$ & $5.27 \pm 3.13$ & $<0.0001$ \\
HADS-A & $3.44 \pm 2.74$ & $5.98 \pm 2.81$ & $<0.0001$ \\
PSWQ & $38.7 \pm 13.23$ & $46.95 \pm 12.22$ & $\mathbf{0 . 0 0 1}$ \\
PAIN VAS & $2.07 \pm 2.02$ & $4.41 \pm 2.07$ & $<0.0001$ \\
ghVAS & $76.73 \pm 20.95$ & $66.6 \pm 20.15$ & $\mathbf{0 . 0 0 5}$ \\
BRAF-NRS & $12.35 \pm 4.51$ & $16.41 \pm 4.76$ & $<0.0001$ \\
PSAQoL & $1.68 \pm 2.47$ & $6.17 \pm 5.15$ & $<0.0001$ \\
EQ-5D SCORE & $0.82 \pm 0.15$ & $0.66 \pm 0.19$ & $<0.0001$ \\
BASFI & $1.53 \pm 1.33$ & $4.26 \pm 1.74$ & $<\mathbf{0 . 0 0 0 1}$
\end{tabular}

Mann-Whitney test. Results are presented as mean \pm SD.

Conclusions: This is the first study assessing the relationship between depression/anxiety and CPDAI in PsA. We have found significantly higher HADS-D, HADS-A, PSWQ scores and worse PROMs in patients with CPDAI >4 compared to those with $\mathrm{CPDAI}<4$. Based on our results there is significant relationship between depression/anxiety, physical function, quality of life and disease activity in psoriatic arthritis.

References:

[1] Haroon M. Expert Rev Clin Immunol. 2016.

[2] Mumtaz A. Ann Rheum Dis. 2011.

Disclosure of Interest: F. Farkas: None declared, N. Ikumi: None declared, A Szentpetery: None declared, B. Kirby Grant/research support from: Abbvie, O. FitzGerald Grant/research support from: Abbvie, Pfizer, BMS, Consultant for: Abbvie, Pfizer, BMS, Novartis, Celgene, Janssen, UCB, Eli Lilly DOI: 10.1136/annrheumdis-2017-eular.6825

\section{AB0756 PRIMARY EFFICACY AND SAFETY OF ADALIMUMAB IN NAIL PSORIASIS FROM THE FIRST 26 WEEKS OF A PHASE-3, RANDOMIZED, PLACEBO-CONTROLLED TRIAL WITH SUBANALYSIS IN PATIENTS WITH AND WITHOUT PSORIATIC ARTHRITIS}

B.E. Elewski ${ }^{1}$, P.A. Rich ${ }^{2}$, F. Behrens ${ }^{3}$, G. Guillet ${ }^{4}$, Z. Geng ${ }^{5}$, O. Reyes Servin ${ }^{5} .{ }^{1}$ University of Alabama at Birmingham, School of Medicine, Birmingham; ${ }^{2}$ Oregon Health and Science University Hospital, Portland, United States: ${ }^{3}$ Goethe University Medical Center, Frankfurt, Germany; ${ }^{4}$ Hopital la Miletrie, Service de Dermatologie, CHU Poitiers, France; ${ }^{5}$ AbbVie Inc., North Chicago, United States

Background: Psoriasis (Ps) disease burden for patients (pts) with psoriasis (Ps) and concomitant fingernail $\mathrm{Ps}$ plus psoriatic arthritis (PsA) is higher compared with pts with Ps alone.

Objectives: We report safety and efficacy of originator adalimumab (ADA) in pts with fingernail Ps, and also for pts with or without concomitant PsA.

Methods: Results are reported from the double-blind PBO-controlled, Period A in which 217 pts with moderate to severe plaque Ps and fingernail Ps were included and randomized $1: 1$ to receive $40 \mathrm{mg} A D A$ every other week (eow) from wk 1 (initial $80 \mathrm{mg}$ dose at wk 0), or matching PBO, for 26 wks. The primary endpoints were the proportion of pts with $\geq 75 \%$ improvement in modified Nail Ps Severity Index (mNAPSI 75) and the proportion of pts with Physician's Global Assessment of Fingernail Psoriasis (PGA-F) of clear (0) or minimal (1) with $\geq 2$-grade reduction from baseline (primary in US only; for regulatory purposes). Missing data were handled by multiple imputation. Safety was assessed using treatment-emergent adverse events (AEs)

Results: Of the 217 randomized pts (108 PBO, 109 ADA), 84.3\% were male; mean age was 46.7 years; $188(86.6 \%)$ completed 26 wks of treatment or early escaped to Period B according to protocol. Both primary endpoints were met: total fingernail mNAPSI 75 was achieved by $3.4 \%$ PBO vs $46.6 \%$ ADA $(p<0.001)$, and PGA-F 0 or 1 with $\geq 2$ grades improvement was achieved by $6.9 \%$ vs $48.9 \%$ $(p<0.001)$. At baseline, $28.6 \%$ had PsA $(29.6 \%$ PBO, $27.5 \%$ ADA) with mean 
duration 7.91 years [SD 8.314]. Total fingernail mNAPSI 75 was achieved by $0.5 \%$ PBO vs $61.5 \%$ ADA of pts with PsA and $4.6 \%$ PBO vs $40.9 \%$ ADA without PsA $(p<0.001$ for both groups). PGA-F 0 or 1 with $\geq 2$-grade reduction was achieved by $4.4 \% \mathrm{PBO}$ vs $59.3 \% \mathrm{ADA}$ with $\mathrm{PsA}$ and $7.9 \% \mathrm{PBO}$ vs $44.9 \%$ ADA without PsA $(p<0.001$ for both groups). Adverse events (AEs) in Period $A$ were reported by $55.6 \%$ PBO vs $56.9 \%$ ADA (with PsA: $56.3 \%$ PBO vs $56.7 \%$ ADA; without PsA: $55.3 \% \mathrm{PBO}$ vs $57.0 \%$ ADA without PsA); serious AEs by $4.6 \% \mathrm{PBO}$ vs $7.3 \% \mathrm{ADA}$ (with PsA: $9.4 \%$ PBO vs $10.0 \%$ ADA; without PsA: $2.6 \%$ PBO vs $6.3 \%$ ADA). Conclusions: The primary results demonstrated that in this population, ADA was more effective than PBO for the treatment of fingernail Ps, and significantly improved signs and symptoms, both overall and regardless of the presence or abscense of PsA; no new safety risks were identified with ADA eow treatment for 26 wks.

Acknowledgements: AbbVie Inc. funded this study and participated in the study design; study research; collection, analysis and interpretation of data; and writing, reviewing and approving of this publication. All authors had access to the data, and participated in the development, review, and approval, and in the decision to submit this publication.

The authors would like to acknowledge Yihua Gu for statistical support, and Jody Bennett, for medical writing support in the production of this abstract; both are employed by AbbVie.

Disclosure of Interest: B. E. Elewski Grant/research support from: Abbvie, Amgen, Boehringer Ingelheim, Celgene, Incyte, Lilly, Merck, Novan, Novartis, Pfizer, Valeant, and Viamet, Consultant for: Anacor, Celgene, Lilly, Novartis, Pfizer, and Valeant, P. A. Rich Grant/research support from: AbbVie, Allergan, Amgen, Anacor, Cassiopea, Dusa, Eli Lilly, Galderma, Janssen, Leo, Meiji, Merck, Novartis, Pfizer, Psolar, Ranbaxy,Sandoz, and Viamet, Consultant for: AbbVie, Eli Lilly, Novartis, Sandoz, Polichem and Valeant, F. Behrens Grant/research support from: AbbVie, Amgen, Celgene, Janssen, Lilly, Novartis, Pfizer, Sandoz, and Sanofi, Consultant for: Abbvie, Chugai, Celgene, Genzyme, Lilly, Novartis, Pfizer, Roche, and Sanofi, G. Guillet Grant/research support from: AbbVie, Z. Geng Shareholder of: AbbVie, Employee of: AbbVie, O. Reyes Servin Shareholder of: AbbVie, Employee of: AbbVie

DOI: 10.1136/annrheumdis-2017-eular.2148

\section{AB0757 IMPACT OF DISEASE ACTIVITY ON PHYSICAL FUNCTION AND HEALTH-RELATED QUALITY OF LIFE IN PATIENTS WITH PSORIATIC ARTHRITIS}

K. Nas ${ }^{1}$, G. Kilic ${ }^{2}$, R. Cevik ${ }^{3}$, A.Z. Dagli ${ }^{3}$, E. Kilic ${ }^{4}$, S. Sag ${ }^{1}$, U. Erkorkmaz ${ }^{5}$, A. Kamanli ${ }^{1}$, I. Tekeoglu ${ }^{1} .{ }^{1}$ Division of Rheumatology and Immunology, Department of Physical Medicine and Rehabilitation, Sakarya University Faculty of Medicine, Sakarya; ${ }^{2}$ Physical Medicine and Rehabilitation, Afyon Kocatepe University Faculty of Medicine, Afyon; ${ }^{3}$ Division of Rheumatology, Department of Physical Medicine and Rehabilitation, Dicle University Faculty of Medicine, Diyarbakir; ${ }^{4}$ Rheumatology Clinic, Afyonkarahisar State Hospital, Afyon; ${ }^{5}$ Department of Biostatistic, Sakarya University Faculty of Medicine, Sakarya, Turkey

Background: Psoriatic arthritis (PsA) is a chronic progressive inflammatory disease characterized by peripheral arthritis, dactylitis, axial joint involvement and extraarticular features. Disease consequences such as chronic pain, severe joint damage and fatigue may adversely effect on a patient's physical function and health-related quality of life $(\mathrm{QoL})$ to perform daily activities.

Objectives: The aim of this study was to investigate the potential relationship between physical function and health-related QoL and disease activity measures in patients with PsA.

Methods: For all participating patients, quality of life, functional and disease activity measures were measured by different ways: Nottingham Health Profile (NHP), psoriatic arthritis quality of life (PsAQoL), Ankylosing Spondylitis Quality of Life (ASQoL), SF36 health survey, Health Assessment Questionnaire (HAQ), BASFI, VAS pain, DAS28, BASDAI and acute phase markers including ESR and CRP.Patients with PSA were discriminated into low and high disease activity according to BASDAI ( $\geq 6$ vs $\leq 4$ ).

Results: A total of 186 patients with PsA (116 female, 70 male, mean age $43,9 \pm 12,6)$ who met CASPAR criteria were included. Their mean symptom duration was $7.9 \pm 9.1$ years. Patients with higher BASDAl score $(\geq 6)$ had significantly higher scores on all important items including health related QoL, fatigue, pain, and functional status. Correlation coefficients between disease activity and various health related QoL measurements were given in Table1. SF36 physical component score was significantly correlated with VAS-pain, BASDAI and DAS28 compared to SF36 mental component. Also, physical activity subscore of NHP was found higher correlated with disease activity indices for PsA in all NHP sections. Other quality of life measurements including PsQoL, HAQ and ASQoL were also significantly correlated with disease activity measurements.

Conclusions: Psoriatic arthritis has a major impact on patients' lives. Variable disease activity measurements were found correlated with all important QoL measurementss including NHP, SF36, PsQoL, HAQ and ASQoL. In patients with PsA, high disease activity may lead to severe impairments in daily activities and influence on participation in society.

Disclosure of Interest: None declared

DOI: 10.1136/annrheumdis-2017-eular.6639

\section{AB0758 AUDIT ON USTEKINUMAB DRUG SURVIVAL IN A DISTRICT GENERAL HOSPITAL VERSUS PSUMMIT 1 TRIAL RESULTS}

\section{G. Tracey, S. Webber. Rheumatology, Weston General, Bristol, United Kingdom}

Background: Psoriatic arthritis (PsA) is an immune mediated inflammatory disorder that affects $10-30 \%$ of patients with psoriasis. Ustekinumab, a monoclonal anti-IL-12/23p40 antibody, is approved for the treatment of PsA and plaque psoriasis ${ }^{1}$ PSUMMIT 1 was one of two phase 3 trials of ustekinumab in adults with active $\mathrm{PsA}^{2} \mathrm{In}$ England, use of medication is subject to guidance from National Institute for Health and Care Excellence (NICE). [TA340] recommend that Ustekinumab is a possible treatment, alone or with methotrexate, for adults with active psoriatic arthritis when treatment with non-biological disease-modifying antirheumatic drugs has not worked well enough if: treatment with tumour necrosis factor (TNF) alpha inhibitors is not suitable for them, or the person has had a TNF alpha inhibitor before ${ }^{3}$ We audited the survival data from our cohort of patients in district general hospital (DGH) against data from PSUMMIT trial.

Objectives: Our objectives were to evaluate drug survival of Ustekinumab in PsA, to compare real world data with that from PSUMMIT trial.

Methods: Our biologics database was searched for patients currently receiving Ustekinumab treatment for Psoriatic Arthritis and those who have had treatment failures. Length of treatment was recorded and any adverse effects which caused the treatment to be stopped. Analysis of treatment non-responders was performed including previous biologics/drug use. We then compared our results to those in the treatment arms (Ustekinumab $45 \mathrm{mg}$ or $90 \mathrm{mg}$ ) of the PSUMMIT trial at week 24 and 52.

Results:

Table 1

\begin{tabular}{lcc} 
& Ustekinumab 45mg & Ustekinumab 90mg \\
\hline DGH $(\mathrm{n}=20)$ & 15 & 5 \\
PSUMMIT $(\mathrm{n}=409)$ & 205 & 204
\end{tabular}

$\begin{array}{lll}\text { PSUMMIT }(\mathrm{n}=409) & 205 & 204\end{array}$

Table 2

\begin{tabular}{lccccc}
\hline & \multicolumn{2}{c}{ DGH } & & \multicolumn{2}{c}{ PSUMMIT } \\
\cline { 2 - 3 } \cline { 5 - 6 } & (Ust 45mg) & (Ust 90mg) & & (Ust 45mg) & (Ust 90mg) \\
\hline Week 24 withdrawal & $4 / 15$ & $0 / 5$ & & $8 / 205$ & $7 / 204$ \\
Reasons: & & & & & 3 \\
$\quad$ Adverse effects & 3 & & & 4 & 3 \\
$\quad$ Inefficacy & 1 & & & 4 & 3 \\
$\quad$ Other (consent, lost follow up) & & & & $17 / 197$ & $15 / 197$ \\
Week 52 withdrawal & $0 / 8$ & $0 / 3$ & & & \\
Reasons: & & & & 2 & 5 \\
$\quad$ Adverse effects & & & & 7 & 3 \\
$\quad$ Inefficacy & & & & 8 & 7 \\
$\quad$ Other (consent, lost follow up) & & &
\end{tabular}

Treatment Failure group (DGH): All patients had had at least one anti-TNF agent prior to Ustekinumab therapy. One patient had trialled 3 , two had two, one had one. They had been stopped either due to inefficacy or intolerance.

Conclusions: Ustekinumab has been shown to be a generally well tolerated drug. Our treatment group had proportionally more treatment failures than the PSUMMIT trial (4/20 $20 \%$ vs $24 / 4095.8 \%$ ). There is the obvious criticism that our patient numbers are very small. For eligibility in PSUMMIT trial the patients had to be anti-TNF naïve. In NHS ENgland, Ustekinumab is not NICE approved as a first line agent except in certain circumstances. Therefore, our patients have had

Abstract AB0757 - Table 1. Correlation coefficients between disease activity and various health related QoL measurements in patients with PsA [r (p)]

\begin{tabular}{|c|c|c|c|c|c|}
\hline & VAS - pain & DAS 28 & BASDAI & ESR & CRP \\
\hline NHP-pain & $0.571(<0.001)$ & $0.326(<0.001)$ & $0.644(<0.001)$ & $0.250(\mathbf{0 . 0 0 3})$ & $0.187(0.027)$ \\
\hline NHP-physical activity & $0.599(<0.001)$ & $0.335(<0.001)$ & $0.652(<0.001)$ & $0.277(<0.001)$ & $0.111(0.191)$ \\
\hline NHP-fatigue & $0.425(<\mathbf{0 . 0 0 1})$ & $0.324(<0.001)$ & $0.530(<0.001)$ & $0.287(<0.001)$ & $0.082(0.337)$ \\
\hline NHP-sleep & $0.236(\mathbf{0 . 0 0 3})$ & $0.118(0.162)$ & $0.308(<0.001)$ & $0.113(0.181)$ & $-0.026(0.764)$ \\
\hline NHP-social isolation & $0.214(\mathbf{0 . 0 0 8})$ & $0.299(<0.001)$ & $0.272(<0.001)$ & $0.080(0.345)$ & $-0.019(0.824)$ \\
\hline NHP-emotional reaction & $0.315(<0.001)$ & $0.281(<0.001)$ & $0.326(<0.001)$ & $0.085(0.315)$ & $-0.023(0.790)$ \\
\hline SF36 physical component & $-0.581(<0.001)$ & $-0.333(\mathbf{0 . 0 0 5 )}$ & $-0.449(<0.001)$ & $-0.346(\mathbf{0 . 0 0 4})$ & $-0.336(\mathbf{0 . 0 0 5 )}$ \\
\hline SF36 mental component & $-0.439(<0.001)$ & $-0.232(0.057)$ & $-0.366(<0.001)$ & $-0.250(\mathbf{0 . 0 3 8})$ & $-0.198(0.102)$ \\
\hline PsAQoL & $0.451(<0.001)$ & $0.285(<0.001)$ & $0.484(<0.001)$ & 0.103.(0.223) & $-0.005(0.955)$ \\
\hline $\mathrm{HAQ}$ & $0.428(<0.001)$ & $0.294(<0.001)$ & $0.386(<0.001)$ & $0.097(0.246)$ & $0.134(0.107)$ \\
\hline ASQoL & $0.459(<0.001)$ & $0.459(<0.001)$ & $0.489(<0.001)$ & $0.220(0.081)$ & $0.068(0.593)$ \\
\hline
\end{tabular}

